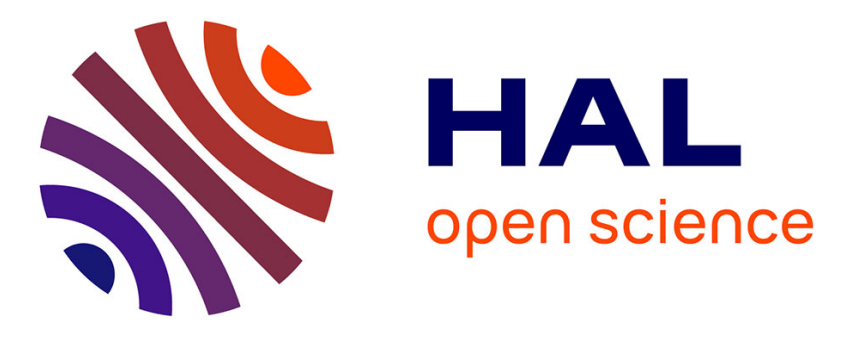

\title{
Ligand-Induced Conformational Changes with Cation Ejection upon Binding to Human Telomeric DNA G-Quadruplexes
}

Adrien Marchand, Anton Granzhan, Keisuke Iida, Yamato Tsushima, Yue Ma, Kazuo Nagasawa, Marie-Paule Teulade-Fichou, Valérie Gabelica

\section{To cite this version:}

Adrien Marchand, Anton Granzhan, Keisuke Iida, Yamato Tsushima, Yue Ma, et al.. LigandInduced Conformational Changes with Cation Ejection upon Binding to Human Telomeric DNA G-Quadruplexes. Journal of the American Chemical Society, 2015, 137 (2), pp.750-756. 10.1021/ja5099403 . hal-01524156

\author{
HAL Id: hal-01524156 \\ https://hal.science/hal-01524156
}

Submitted on 17 May 2017

HAL is a multi-disciplinary open access archive for the deposit and dissemination of scientific research documents, whether they are published or not. The documents may come from teaching and research institutions in France or abroad, or from public or private research centers.
L'archive ouverte pluridisciplinaire HAL, est destinée au dépôt et à la diffusion de documents scientifiques de niveau recherche, publiés ou non, émanant des établissements d'enseignement et de recherche français ou étrangers, des laboratoires publics ou privés. 
This document is the Accepted Manuscript version of a Published Work that appeared in final form in the Journal of the American Chemical Society, copyright (C) American Chemical Society after peer review and technical editing by the publisher. To access the final edited and published work see http://dx.doi.org/10.1021/ja5099403

\section{Ligand-induced conformational changes with cation ejection upon binding to human telomeric DNA G-quadruplexes}

Adrien Marchand,, ${ }^{1,2}$ Anton Granzhan, ${ }^{3}$ Keisuke Iida, ${ }^{4}$ Yamato Tsushima, ${ }^{4}$ Yue Ma,4 Kazuo Nagasawa, ${ }^{4}$ Marie-Paule Teulade-Fichou ${ }^{3}$ and Valérie Gabelica, ${ }^{1,2,}{ }^{*}$

${ }^{1}$ Univ. Bordeaux, IECB, ARNA Laboratory, 3360o Pessac, France. ${ }^{2}$ Inserm, U869, ARNA Laboratory, 33000 Bordeaux, France. 3 Institut Curie, Section Recherche, CNRS UMR176, Centre Universitaire Paris XI, Bat. 110, 91405 Orsay, France. 4 Tokyo University of Agriculture \& Technology. 224-16 Naka-cho. 84-8588 Koganei-shi, Tokyo, Japan.

KEYWORDS. DNA structures - Ligand - G-quadruplexes - Mass spectrometry - Molecular recognition.

\footnotetext{
ABSTRACT: The rational design of ligands targeting human telomeric DNA G-q uadruplexes is a complex problem due to the structural polymorphism that these sequences can adopt in physiological conditions. Moreover, the ability of ligands to switch conformational equilibria between different G-quadruplex structures is often overlooked in docking approaches. Here, we demonstrate that three of the most potent G-quadruplex ligands (36oA, Phen-DC3

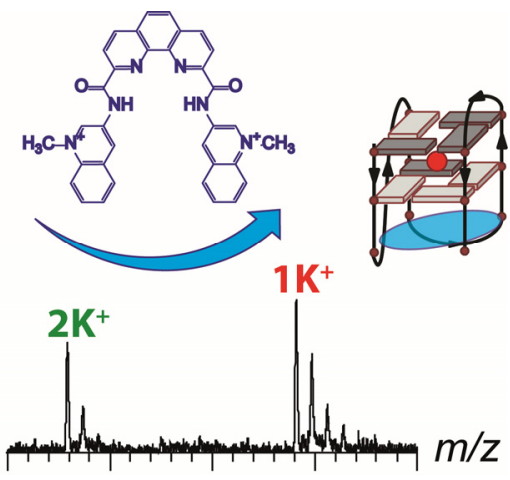
and pyridostatin) induce conformational changes of telomeric DNA G-quadruplexes to an antiparallel structure (as determined by circular dichroism) containing only one specifically coordinated $\mathrm{K}^{+}$(as determined by electrospray mass spectrometry), and hence presumably only two consecutive G-quartets. Control ligands TrisQ, known to bind preferentially to hybrid than to antiparallel structures, and L2H2-6M(2)OTD, known not to disrupt the hybrid-1 structure, did not show such $\mathrm{K}^{+}$removal. Instead, binding of the cyclic oxazole $\mathrm{L}_{2} \mathrm{H}_{2}-6 \mathrm{M}(2) \mathrm{OTD}$ was accompanied by the uptake of one additional $\mathrm{K}^{+}$. Also contrasting with telomeric G-quadruplexes, the parallel-stranded Pu24-myc G-quadruplex, to which Phen-DC3 is known to bind by end-stacking, did not undergo cation removal upon ligand binding. Our study therefore evidences that very affine ligands can induce conformational switching of the human telomeric G-quadruplexes to an antiparallel structure, and that this conformational change is accompanied by removal of one inter-quartet cation.
} 


\section{INTRODUCTION}

There is now strong evidence that guanine-rich sequences can form G-quadruplex $\left(\mathrm{G}_{4}\right)$ structures in human cells, ${ }^{1}$ including in the regions of telomeres that comprise a 3 '-overhang consisting of d(TTAGGG) $)_{n}$ repeats. Ligands targeting telomeric G-quadruplexes are developed as anticancer therapeutics, and some were shown to perturb telomere structure. ${ }^{2-5}$ Current screening assays usually probe the ligand ability to bind to pre-folded G-quadruplexes with both high affinity and high selectivity as compared to double stranded DNA.

The rational design of telomeric $\mathrm{G}_{4}$ ligands is however further complicated by the polymorphism that these sequences adopt in vitro ${ }^{6}$ and the ensuing uncertainties about which structures are relevant in vivo. ${ }^{-10}$ For example, four-repeat sequences containing the central core $\mathrm{d}\left(\mathrm{GGG}(\mathrm{TTAGGG})_{3}\right)$ have been shown to be able to form three different G-quadruplex structures in $100 \mathrm{mM} \mathrm{K}^{+}$: Hybrid-1 formed by sequences $24 \mathrm{TTG}^{11}$ (dTTGGG(TTAGGG) $\mathrm{A}$, Fig. 1A) or $23 \mathrm{TAG}$ (dTAGGG(TTAGGG) $)_{3}$ ), Hybrid-2 formed by 26 TTA $^{12}$ (d(TTAGGG) ${ }_{4}$ TT, Fig. 1 B) and the two-quartet Hybrid-3 structure $^{13}$ formed by 22 GT (dGGG(TTAGGG) 3 T, Fig. 1C).
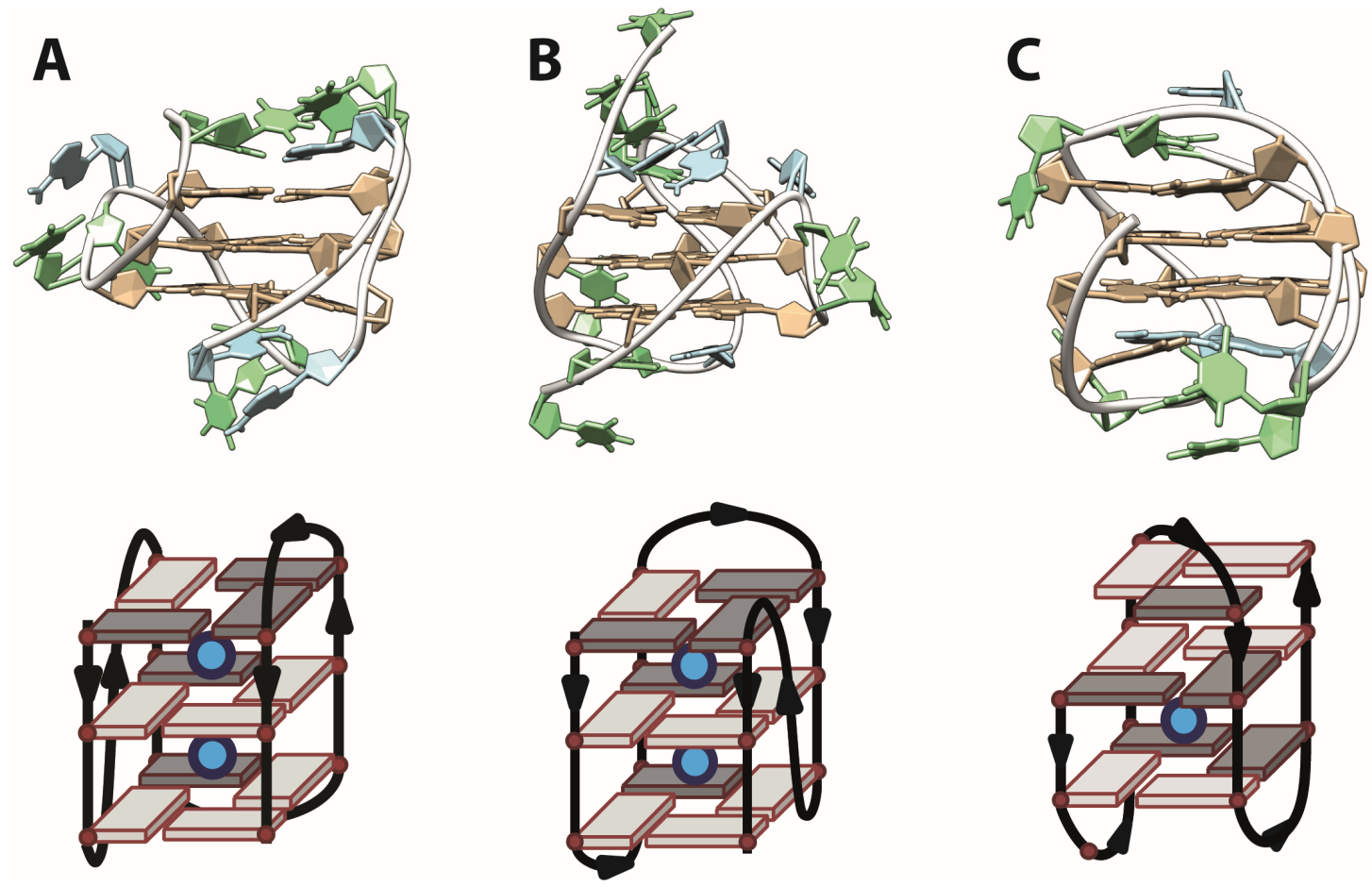

FIGURE 1. Top, structures of human telomeric G-quadruplexes obtained by NMR in $70 \mathrm{mM} \mathrm{K}{ }^{+}$and $20 \mathrm{mM} \mathrm{K} \mathrm{HPO}_{4} / \mathrm{KH}_{2} \mathrm{PO}_{4}$. Bottom, their respective schematic view with expected cation binding sites in-between successive G-quartets. A, Hybrid-1 formed by 24TTG - PDB ID: 2GKU." B, Hybrid2 formed by 26 TTA - PDB ID: 2 JPZ. ${ }^{12}$ C, Hybrid-3 formed by 22 GT - PDB ID: 2 KF8. ${ }^{13}$ For full sequences, see main text. 
Some ligands were previously reported to bind better to the $\mathrm{Na}^{+}$-structure or to the $\mathrm{K}^{+}$-structure, as deduced from thermal denaturation and fluorescence displacement assays, ${ }^{14}$ but these studies did not discuss possible ligand-induced changes in G-quadruplex conformation. Other groups documented ligand-induced formation of particular G-quadruplex structures, ${ }^{15}{ }^{-18}$ but with few exceptions $^{19}$ most of these studies were carried out in the absence of salt, so the relevance to physiologically relevant conditions remains unclear.

We studied here the interaction of ligands Phen-DC $3{ }^{20} 360 \mathrm{~A},{ }^{21,22}$ pyridostatin ${ }^{23}$ (abbreviated PDS), TrisQ ${ }^{24}, \mathrm{~L}_{2} \mathrm{H}_{2}-6 \mathrm{M}(2) \mathrm{OTD}^{25}$ (abbreviated $\mathrm{L}_{2} \mathrm{H}_{2}$ ) and $\mathrm{TMPyP}_{4}$ (ligand structures in Chart 1, molar extinction coefficients in Supporting Information S1) with the different human telomeric sequences 26TTA, 24TTG, 23TAG and 22GT. Some of these ligands were previously shown to be very potent $\mathrm{G}_{4}$ binders and therefore have been used as $\mathrm{G}_{4}$ probes in a variety of biological systems and in cell-based assays. For example, both 360A and PDS promote G4 specific DNA damage and induce growth arrest in human cancer cells. ${ }^{26,27}$ In addition functional derivatives of both compounds have been used for $\mathrm{G}_{4}$ imaging, ${ }^{26}$ pull down assays, ${ }^{28}$ in vitro selection of $\mathrm{G}_{4} \mathrm{DNA}^{29}$ and more recently to photo-cross-link G-quadruplexes. ${ }^{30}$ Finally, transcriptomic studies showed that both Phen-DC 3 and 36oA affect the expression of genes with $\mathrm{G}_{4}$ motif in their transcription start site. ${ }^{31}$ More specifically, Phen-DC3 has been used to trigger quadruplex-dependent genetic instability in yeast ${ }^{32,33}$ and subsequently was shown to inhibit the unwinding activity of FANCJ helicase. 34

Despite their wide use, the exact binding mode of these ligands to telomeric G-quadruplex is not known. Indeed, only a few structures of the human telomeric sequence in presence of ligands have been released. Except for $\mathrm{L}_{2} \mathrm{H}_{2}$ for which NMR revealed binding to the 24TTG sequence without changing the hybrid-1 G-quadruplex topology, ${ }^{25}$ all reported structures of the human telomeric DNA interacting with ligands are parallel G-quadruplexes obtained by x-ray crystallography. ${ }^{35-41}$ Unfortunately, crystallization is known to bias the structural population by selecting the parallel topology. ${ }^{42}$

There is therefore a strong need for in-solution assays able to quickly assess ligand binding affinity and binding mode in polymorphic G-quadruplexes such as the human telomeric sequence. Here we used native electrospray mass spectrometry (ESI-MS) to assay ligand ability to bind to G-quadruplexes. Thanks to the mass separation, single cation binding can be distinguished in the free and bound quadruplexes. Our experiments revealed ligand-induced cation ejection upon binding, thereby providing novel insight into the ligand binding mode. 


\section{Chart 1. Ligand structures}

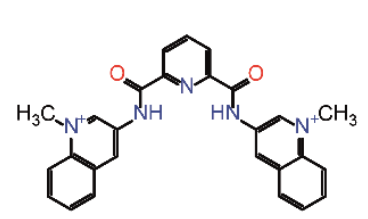

$360 \mathrm{~A}$

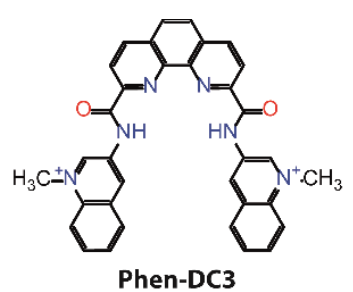

Phen-DC3
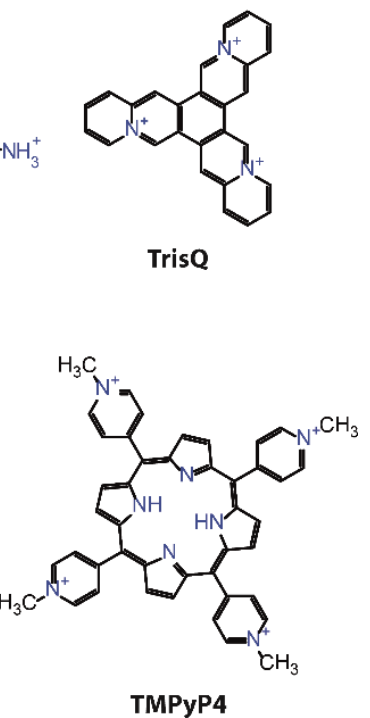

TMPyP4

L2H2

\section{RESULTS AND DISCUSSIONS}

Ligand and cation binding, simultaneously probed by ESI-MS, reveals $\mathrm{K}^{+}$ejection upon binding of $360 A$, Phen-DC 3 or PDS to telomeric DNA G-quadruplexes.

We recently reported a sample preparation method in $100 \mathrm{mM}$ trimethylammonium acetate (TMAA) and up to $1 \mathrm{mM} \mathrm{KCl,} \mathrm{which} \mathrm{allows} \mathrm{recording} \mathrm{ESI-MS} \mathrm{spectra} \mathrm{in} \mathrm{conditions} \mathrm{where} \mathrm{the} \mathrm{so-}$ lution fold is very similar as in $100 \mathrm{mM} \mathrm{K}^{+}$, as indicated by CD spectroscopy, ${ }^{43}$ although the fraction folded at room temperature is somewhat lesser in $100 \mathrm{mM}$ TMAA and $1 \mathrm{mM} \mathrm{KCl}$ than in $100 \mathrm{mM}$ $\mathrm{K}^{+}$(see melting experiments in supporting Figure S2 and separate discussion of $22 \mathrm{GT}$ below). In TMAA/KCl conditions, ESI-MS allows the direct simultaneous measurement of ligand and cation binding stoichiometries from $\mathrm{KCl}$ solutions. On the contrary to the commonly used ammonium acetate conditions, ${ }^{44}$ the determination of potassium ion binding stoichiometry by ESI-MS from $\mathrm{TMAA} / \mathrm{KCl}$ preparations is robust and independent of instrument choice or tune. 43

Figure 2 shows the ESI-MS spectra of $5 \mu \mathrm{M}$ 24TTG in $100 \mathrm{mM}$ TMAA and $1 \mathrm{mM} \mathrm{KCl}$ without ligand (Figure 2A), a reference single-strand 24nonG 4 (dTGGGATGCGACAGAGAGGACGGGA) without ligand (Figure $2 \mathrm{~B}$ ), and $5 \mu \mathrm{M} 24 \mathrm{TTG}$ incubated for three days at room temperature in the 
presence of $5 \mu \mathrm{M}$ ligand (Figures $2 \mathrm{C}-\mathrm{H}$ ) (1 day to 1 month, or annealing did not make any difference). Figure 2 shows the mass spectral region corresponding to free $\mathrm{G}_{4}$ and the 1:1 complex in the 5- charge state. Full-scale spectra in SI (Figure S3) illustrate that the 2:1 complex abundance is very minor. Ligand relative affinities are estimated from the relative intensities of the peaks without and with ligands. The relative abundance of 1:1 complex relative to free $\mathrm{G}_{4}$ ranked: Phen-DC $3 \sim$ TrisQ 360A > PDS L2H2 > TMPyP4. Similar ranking was obtained with 26TTA, 23TAG and 22GT (Figure $\mathrm{S}_{4}, \mathrm{~S}_{5}$ and $\mathrm{S6}$, respectively). Tests with a reference hairpin duplex (ds26) allowed us to assess ligand binding selectivity (Figure $\mathrm{S}_{7}$ ). TMPyP4 binds very strongly to the hairpin duplex, in line with its known total lack of selectivity. TrisQ binds to the duplex, but less well as to the G-quadruplexes. The other four ligands do not bind to the hairpin and are confirmed as very selective G-quadruplex binders.

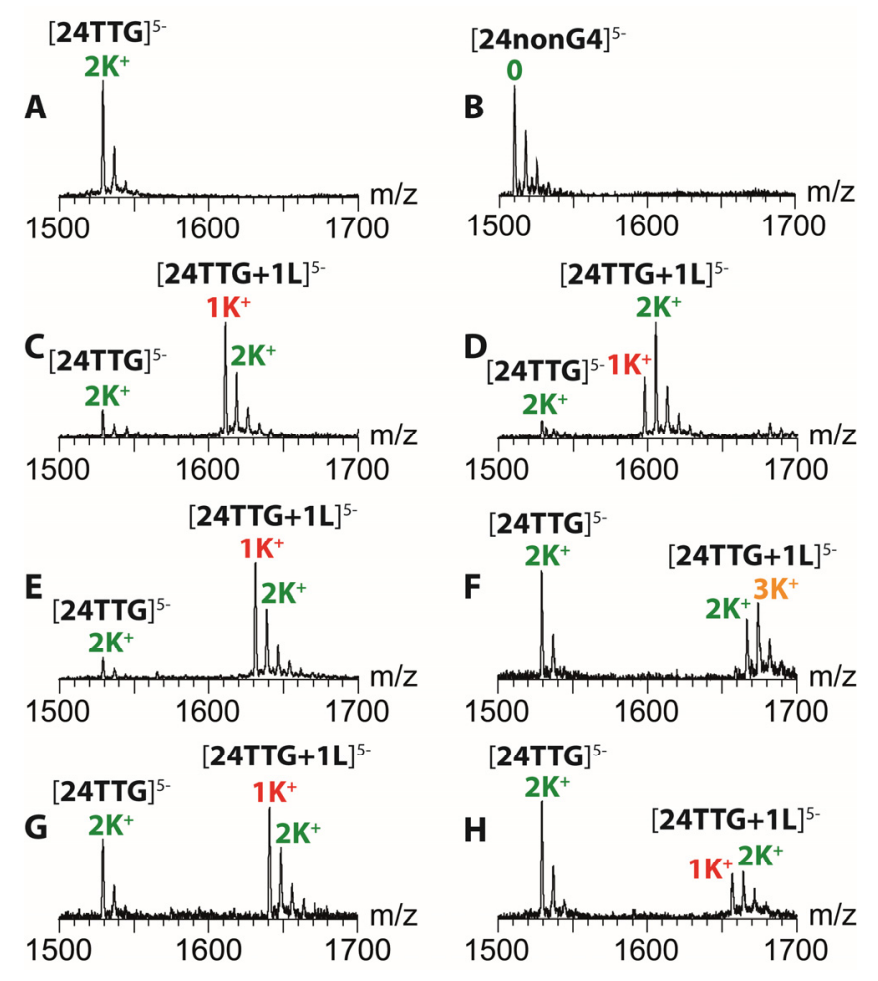

FIGURE 2. Electrospray mass spectra (all in in $100 \mathrm{mM} \mathrm{TMAA}+1 \mathrm{mM} \mathrm{KCl}$ ) of (A) $5 \mu \mathrm{M} 24 \mathrm{TTG}$ alone, (B) 24nonG 4 alone, $(\mathrm{C}-\mathrm{H}) 5 \mu \mathrm{M} 24 \mathrm{TTG}$ incubated 3 days with $5 \mu \mathrm{M}$ of each ligand: (C) $360 \mathrm{~A}$, (D) TrisQ, (E) Phen-DC3, (F) L2H2, (G) PDS and (H) TMPyP4.

Labels in Figure 2 also show the major specific $\mathrm{K}^{+}$binding stoichiometries in each complex. Without ligand, 24TTG specifically binds two $\mathrm{K}^{+}$ions (Figure 2A), in line with its known threequartet NMR structure (Figure $1 \mathrm{~A}$ ), and with the known inter-quartet octahedral $\mathrm{K}^{+}$coordination mode. The additional $\mathrm{K}^{+}$binding (third and fourth adduct) detected on the right hand side of the peak shows the same distribution as for 24 nonG $_{4}$ (first and second adduct) and are therefore non- 
specifically bound adducts. In order to distinguish and quantify quadruplex-specific $\mathrm{K}^{+}$adducts, we used the following method described by Klassen's group. ${ }^{45}$ Briefly, a control molecule, as similar as possible to the analyzed molecule but lacking the specific $\mathrm{K}^{+}$binding sites, is used as a reference. The intensity ratios of the $\mathrm{K}^{+}$-bound versus unbound reference are taken as the signature of the nonspecific adducts distribution. This intensity distribution is then used to subtract nonspecific adducts contribution for other analytes. Using non- $\mathrm{G}_{4}$ forming sequences (as confirmed by CD, see Figure S8) with same guanine content and length as each quadruplex, we reconstructed the specific $\mathrm{K}^{+}$distributions for each complex in the form of bar graphs (see supporting text and Figure S9 for detailed method and Figure Sio for results), which reflect what is annotated in the raw mass spectra of Figure 2.

Strikingly, the $\mathrm{K}^{+}$binding stoichiometry is affected by ligand binding, in a ligand-dependent manner, and the same behavior is observed for all four variants of the human telomeric sequence (24TTG, 23TAG, 26TTA and 22GT; see Figure S10). For 360A, Phen-DC3 and PDS, a single $\mathrm{K}^{+}$ion is bound to the 1:1 complex, while two are bound to the free $\mathrm{G}_{4}$. In contrast, TrisQ only very partially displaced one cation.

Because $\mathrm{K}^{+}$is supposedly coordinated in-between consecutive G-quartets, a 1:1:1 (DNA:ligand: $\mathrm{K}^{+}$) stoichiometry suggests that the ligand-bound structure contains only two consecutive G-quartets. It is particularly interesting that the 24 TTG sequence, one of the most monomorphic variants of the human telomeric sequence in $\mathrm{KCl}$, as shown by $\mathrm{NMR},{ }^{11}$ is capable of such ligand-induced rearrangement.

In order to prove that the observed stoichiometries are indeed the ones present in solution and are not due to some kind of mass spectrometry artifact, we repeated the experiment with $\mathrm{L}_{2} \mathrm{H}_{2}$, which was previously shown by NMR to bind to 24 TTG without changing its topology. ${ }^{25}$ The two inter-quartet $\mathrm{K}^{+}$binding sites should therefore be preserved. Moreover, cyclic oxazoles might even capture one extra $\mathrm{K}^{+}$ion by coordination, in the same way as telomestatin. ${ }^{46,47}$ This is exactly what we observe in our mass spectra: the 1:1 DNA:ligand complex was detected with either two or three $\mathrm{K}^{+}$ions bound (Figure $2 \mathrm{~F}$ ).

As a second control we used the Pu24 c-myc sequence ( $\mathrm{dTG}_{\mathrm{AG}} \mathrm{TG}_{4} \mathrm{AG}_{3} \mathrm{TG}_{4} \mathrm{AAG}_{2}$ ). Indeed, the recently published structure of Pu24 interacting with Phen-DC 3 revealed that this ligand did not disrupt the parallel-stranded three-quartet structure. ${ }^{8}$ When analyzed by ESI-MS in the TMAA/KCl preparation (Figure S11), the Pu24 sequence retains the expected two $\mathrm{K}^{+}$ions, both without ligand and with all ligands including Phen-DC3. Coordination of a third $\mathrm{K}^{+}$ion with $\mathrm{L}_{2} \mathrm{H}_{2}$ is observed as well. The CD spectra were not affected upon ligand binding to Pu24 (Figure S12). These controls highlight that cation removal upon binding of $360 \mathrm{~A}$, Phen-DC 3 and PDS is a binding mode that is peculiar to the human telomeric G-quadruplexes. 


\section{Circular dichroism spectroscopy indicates that the G-quartets in the 1 - $\mathrm{K}^{+}$form have alter-}

nated stacking.

In order to obtain information about conformational changes occurring upon ligand binding and cation ejection, we performed $\mathrm{CD}$ experiments on the same solutions. The $\mathrm{CD}$ spectra give information on the stacking mode of consecutive guanines. Type-I spectra (positive peak at $265 \mathrm{~nm}$, negative peak at $240 \mathrm{~nm}$ ) indicate guanine stacking all in the same orientation (e.g., anti-anti), type-II spectra (positive peaks at 265 and $295 \mathrm{~nm}$, negative peak at $240 \mathrm{~nm}$ ) indicate guanine stacking partly in the same, and partly in alternating orientation (e.g., anti-syn or syn-anti), and typeIII spectra (positive peaks at 295 and $240 \mathrm{~nm}$, negative peak at $260 \mathrm{~nm}$ ) indicate guanine stacking in exclusively alternating orientations. ${ }^{49}$ If mixtures are present, the $C D$ spectrum will be the weighted average spectrum of all conformers present in solution and may resemble Type-II spectra.

Figure $3 \mathrm{~A}$ illustrates the $\mathrm{CD}$ spectral changes observed when adding ligands to $24 \mathrm{TTG}$ (hybrid-1 structure with CD spectrum of Type II). In the case of Phen-DC3, 360A and PDS, the CD spectra are shifting to Type-III, indicating exclusively alternated stacking. In the corresponding ESI-MS spectra, almost all 24 TTG is bound to $360 \mathrm{~A}$ or Phen-DC3 in a 1:1:1 (DNA:ligand: $\mathrm{K}^{+}$) stoichiometry. The $1-\mathrm{K}^{+}$and presumably 2-quartet, ligand-bound structure has therefore the alternate G-quartet stacking typically encountered in antiparallel folds. For PDS, ESI-MS tells us that some free 24TTG remains, explaining the lesser shift of the $\mathrm{CD}$ spectrum compared to $360 \mathrm{~A}$ and Phen-DC3, but the ligand-bound structure has the same characterisctics. In the cases of TrisQ and $\mathrm{L}_{2} \mathrm{H}_{2}$, the CD spectra of 24TTG are almost unaffected. The same results are obtained for 26TTA, 23TAG and 22GT (supporting Figures $\mathrm{S}_{13}, \mathrm{~S}_{14}$ an $\mathrm{S}_{15}$, respectively).

Figure ${ }_{3} \mathrm{~B}$ shows the $\mathrm{CD}$ spectra recorded in $100 \mathrm{mM} \mathrm{KCl}$. In $100 \mathrm{mM} \mathrm{TMAA}+1 \mathrm{mM} \mathrm{KCl}$ conditions, the $\mathrm{CD}$ spectrum of $24 \mathrm{TTG}$ alone is the same as in $100 \mathrm{mM} \mathrm{KCl} .{ }^{33}$ The ligand ability to induce a shift to the Type-III spectrum is still observed, although to a lesser extent than in TMAA/KCl, probably due to the higher stability of the hybrid-1 structure in high $\mathrm{KCl}$ concentration. Phen- $\mathrm{DC}_{3}$ is clearly the most prone to change the G-quadruplex structure upon binding, even in $100 \mathrm{mM} \mathrm{KCl}$.

\section{Discussion: some of the most affine and selective G-quadruplex ligands display a new binding mode with ligand-induced cation ejection.}

The ligand-bound G-quadruplex structure containing only two quartets (as deduced from the number of $\mathrm{K}^{+}$ions coordinated) displays alternated stacking (as deduced from $\mathrm{CD}$ ). Conversely, the ligands that do not displace cations do not lead to such antiparallel-type CD spectra. There are mainly three hypotheses on what this ligand-bound G-quadruplex structure could be (Figure 4): (1) a structure with ligand intercalation (the ligand would take the place of one $\mathrm{K}^{+}$), (2) a hybrid-1 
or hybrid-2 type structure with the quartet in homo-stacking disrupted, or (3) a hybrid-3 type structure with 2 quartets and with the triplet stacking hampered by ligand end-stacking.
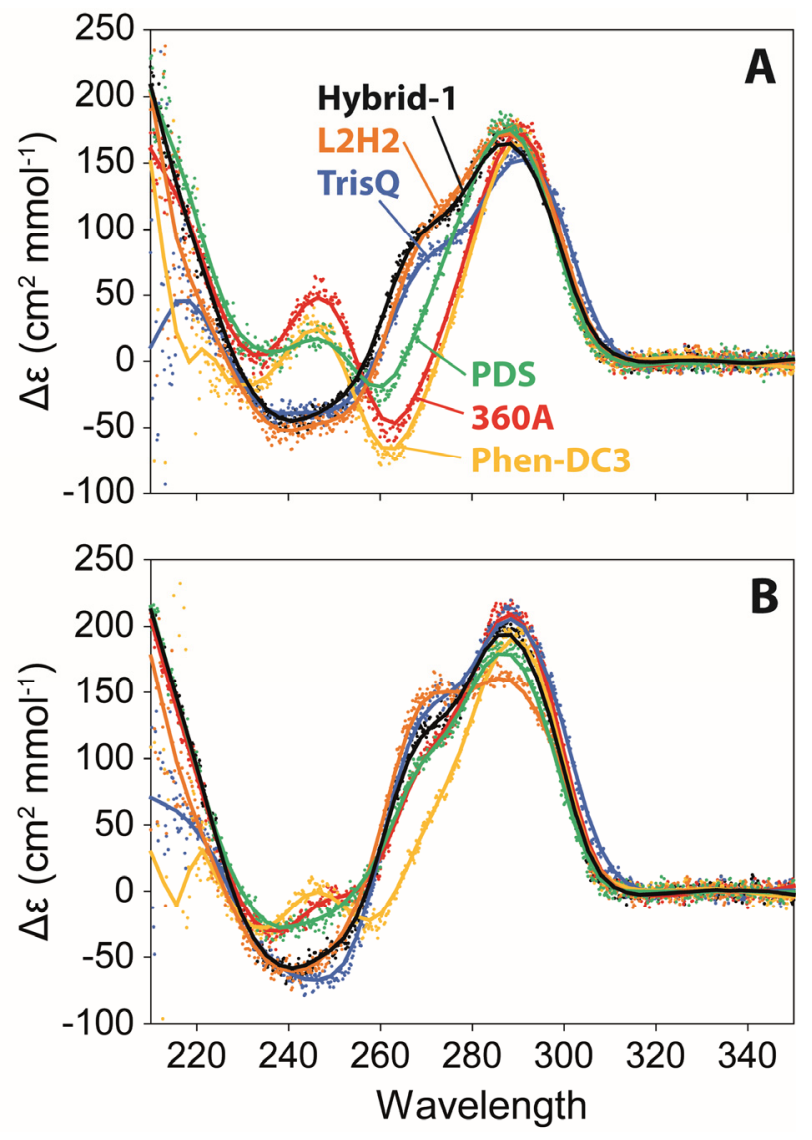

FIGURE 3. Circular dichroism spectra of $5 \mu \mathrm{M} 24 \mathrm{TTG}$ in (A) $100 \mathrm{mM} \mathrm{TMAA}+1 \mathrm{mM} \mathrm{KCl}$ and in (B) $20 \mathrm{mM} \mathrm{KH} \mathrm{KO}_{4} / \mathrm{K}_{2} \mathrm{HPO}_{4}+7 \mathrm{O} \mathrm{mM} \mathrm{KCl}$. CD spectra were recorded after 3 days without ligand (black) and in the presence of Phen- $\mathrm{DC}_{3}$ (yellow), 36oA (red), PDS (green), $\mathrm{L}_{2} \mathrm{H}_{2}$ (orange) and TrisQ (blue).
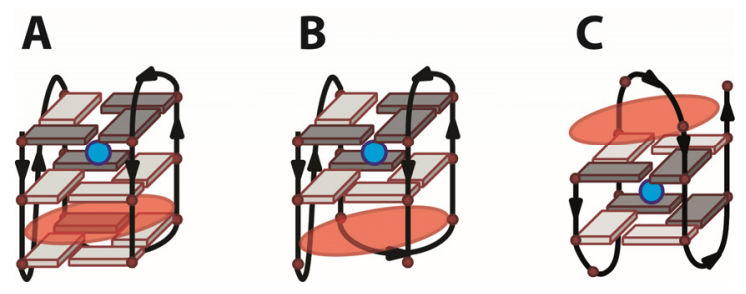

FIGURE 4. Ligand binding modes compatible with our data: (A) an intercalated ligand on a hybrid2 G-quadruplex, (B) a ligand disrupting a quartet of a hybrid-2 $\mathrm{G}_{4}$ and (C) a ligand taking the place of the triplet of guanines in a hybrid-3 $\mathrm{G}_{4}$. 
To our knowledge, only one study to date has reported ligand intercalation in G-quadruplexes, with $\mathrm{TMPyP}_{4}$ intercalation in long parallel G-wires. ${ }^{50}$ However, intercalation in the G-wires only occurred in absence of salt. Here, true intercalation (Fig. 4A) would probably involve a strong structural rearrangement with first a $\mathrm{G}$-quartet opening and $\mathrm{K}^{+}$displacement before closing again the G-quartet by sandwiching the ligand. G-quartet opening and $\mathrm{K}^{+}$displacement are of course unfavorable thermodynamically, but in turn, four guanines will gain conformational degrees of freedom, and that a solvated $\mathrm{K}^{+}$will be released from the complex, so the penalty might be compensated by the free energy gained upon ligand binding. However, it seems difficult to assume that re-closing of the G-quartet on the other side of the ligand would be thermodynamically favorable, because the small enthalpically favorable contribution due to extra stacking would be compensated entropically by reducing the degrees of freedom. The binding mode of Figure $4 \mathrm{~B}$ is therefore more likely than that of Figure $4 \mathrm{~A}$.

The second hypothesis, namely the disruption of G-quartets (Figure $4 \mathrm{~B}$ ), was proposed previously for an anthrathiophenedione on telomeric $\mathrm{G}_{4},{ }^{19}$ for $\mathrm{TMPyP}_{4}$ on an $\mathrm{RNA} \mathrm{G}_{4},{ }^{51}$ and for a triarylpyridine ligand on c-kitı and c-kit2..$^{2}$ However in all reports these ligands were promoting total unfolding of the G-quadruplexes. In our case the melting temperature of the G-quadruplexes with the ligands are higher than without ligand (see supporting information Figures S16 and S17), meaning that the ligand-bound 2-quartet structure is more thermally stable than the starting structure. Also the broad melting transitions of $360 \mathrm{~A}$ and Phen-DC 3 complexes are typical of multi-step denaturation that may indicate conformational rearrangements. ${ }^{53}$ However, the thermal denaturation transition is narrower and at lower temperature for PDS, indicating that ligand binding mode and thermal stability are not necessarily linked: these are two different tenets of ligand binding that must both be characterized. For example, the relative abundance of 1:1 complex relative to free $\mathrm{G}_{4}$ at RT (see Figures $\mathrm{S}_{3}-\mathrm{S} 6$ ) correlates well with the $T_{\mathrm{m}}$ only for the three ligand sharing the newly described binding mode: Phen- $\mathrm{DC}_{3}>360 \mathrm{~A}>\mathrm{PDS}$. Ligand $\mathrm{L}_{2} \mathrm{H}_{2}$, although having a different binding mode without disturbing the structure and with an additional potassium ion, also fit in this trend, with an affinity in the same range as that of PDS. Ligand TrisQ, with its propensity to induce more parallel structures either at RT (with 26TTA, see Fig. S17) or at higher temperature (with 24TTG, see Fig. S16), does however follow different rules. In general, studies of the ligand binding mode and ligand-induced conformational changes should also consider the temperature dependence of these phenomena.

The last hypothesis is the ligand-induced conformational selection of a hybrid-3 structure such as that formed predominantly by $22 \mathrm{GT}$. This structure contains only 2 quartets at $100 \mathrm{mM} \mathrm{K}$, plus a triplet of guanines stacked on one terminal quartet. ${ }^{13}$ Notably, this 2-quartet structure is as thermally stable as the other 3-quartet structures, ${ }^{13}$ (Figure S2) and therefore extra stabilization by a 
ligand sounds reasonable. To further explore the correlation between the potassium binding stoichiometry and the hybrid-3 structure, we titrated $22 \mathrm{GT}$ by $\mathrm{KCl}$, from o to $1 \mathrm{mM}$ using ESI-MS and $\mathrm{CD}$, and up to $100 \mathrm{mM}$ using $\mathrm{CD}$ (Figure S18). In pure TMAA and no $\mathrm{KCl}$, the DNA remains unfolded. ${ }^{43}$ Interestingly, at $200 \mu \mathrm{M} \mathrm{KCl}$ concentration, the main stoichiometry observed is $1 \mathrm{~K}^{+}$per DNA strand and the corresponding $C D$ spectrum is purely antiparallel, just like in the presence of ligands $360 \mathrm{~A}$, Phen-DC 3 and PDS. We therefore assign the first $\mathrm{K}^{+}$binding event to the binding site between the two full G-quartets of hybrid-3. At $1 \mathrm{mM} \mathrm{KCl}$ concentration, a second potassium ion binding site is detected, which we attribute to the filling of a second binding site between the G-triplet and one G-quartet. In the same solution, the CD spectra show that the hump at $270 \mathrm{~nm}$, attributed to the stacking of the triplet, ${ }^{49}$ is increasing accordingly. Ligand binding to the hybrid-3 by end-stacking on the top quartet would disrupt triplet stacking, and this binding mode is therefore compatible with all our observations.

\section{CONCLUSIONS}

In summary, we evidenced here that ligands can induce conformational changes in human telomeric G-quadruplexes at physiological ionic strength and in $\mathrm{KCl}$. Three ligands (Phen-DC3, 36oA and PDS), among the most potent described to date, were found to favor $\mathrm{G}_{4}$ structures with only one $\mathrm{K}^{+}$, hence two consecutive G-quartets, and hetero-stacking between these G-quartets. This ligand-induced $\mathrm{K}^{+}$ejection could be due to a quartet disruption of hybrid structures or to the conformational selection of the hybrid-3 structure.

Interestingly, only the three most flexible ${ }^{54}$ of the ligands tested here, all based on the dicarboxamide scaffold (Phen-DC $3,360 A$ and PDC), are capable of ejecting $\mathrm{K}^{+}$cation upon binding, while stabilizing the antiparallel 2-quartet G-quadruplex structure. It would be interesting in the future to explore the enthalpy and entropy contributions to ligand binding in those particular cases, and to partition the intrinsic folding thermodynamic parameters from the polyelectrolyte and water capture/release contributions. Although high-resolution atomistic methods would be required to determine the exact binding mode, our work opens new ideas on possible G-quadruplex ligand binding modes. It also highlights that thanks to ESI-MS monitoring of cation binding, hints on the ligand binding mode can be obtained with small amounts of sample and even in the presence of polymorphic structures. The technique is amenable to higher-throughput screening of ligands.

Our results also have important implications for the design of ligands targeting polymorphic Gquadruplexes such as the human telomeric sequence. The availability of high resolution structures makes it tempting to develop drug design programs based on the lock-and-key model. In contrast, we show here that several ligands with high G-quadruplex affinity and specificity induce structural changes in telomeric G-quadruplexes, and that induced fit or conformational selection must therefore be taken into account for the drug design. 


\section{EXPERIMENTAL SECTION}

Materials. Oligonucleotides were purchased lyophilized and RP-cartridge purified from Eurogentec (Seraing, Belgium) and used without further purification. We used the following nomenclature for the DNA sequences: 26TTA $=\mathrm{d}\left((\mathrm{TTAGGG})_{4} \mathrm{TT}\right)$; $24 \mathrm{TTG}=\mathrm{d}\left(\mathrm{TT}(\mathrm{GGGTTA})_{3} \mathrm{GGGA}\right)$; 23 TAG $=\mathrm{d}\left(\mathrm{TA}(\mathrm{GGGTTA})_{3} \mathrm{GGG}\right) ; \quad 22 \mathrm{GT}=\mathrm{d}\left((\text { GGGTTA })_{3}\right.$ GGGT $) ;$ Pu24 $\quad$-myc $=$ $\mathrm{d}$ (TGAGGGTGGGGAGGGTGGGGAAGG), $24 \mathrm{nonG}_{4}=\mathrm{d}($ TGGGATGCGACAGAGAGGACGGGA), 22nonG $4=\mathrm{d}($ GGGATGCGACAGAGAGGACGGG), 23nonG4 $\mathrm{d}\left(\right.$ TGGGATGCGACAGAGAGGACGGG), $26 \mathrm{nonG}_{4}=\mathrm{d}($ TTGGGATGCGACAGAGAGGACGGGAT), and $\mathrm{ds}_{2} 6=\mathrm{d}\left(\mathrm{CA}_{2} \mathrm{TCG}_{2} \mathrm{ATCGA}_{2} \mathrm{~T}_{2} \mathrm{CGATC}_{2} \mathrm{GAT}_{2} \mathrm{G}\right)$. Analyzed solutions contained $5 \mu \mathrm{M}$ DNA diluted from 200- $\mu \mathrm{M}$ stock solution. Water was nuclease-free from Ambion (Applied Biosystems, Lennik, Belgium). The concentrations of the initial stocks solutions were measured by UV absorbance at $260 \mathrm{~nm}$ on a Uvikon XS. Molar absorption coefficients were obtained on the IDT website and corrected using Cavaluzzi-Borer correction. ${ }^{55} 100 \mathrm{mM}$ trimethylammonium acetate (TMAA, Ultra for HPLC, Fluka analytical) was used to fix the ionic strength and the solutions were doped with up to $1 \mathrm{mM} \mathrm{KCl}$ (>99.999\%, Sigma) as described previously.43 Ligands were either synthesized as described elsewhere $\left(360 A\right.$ iodide salt, Phen-DC 3 methylsulfonate salt, ${ }^{20}$ TrisQ bromide salt, ${ }^{24}$ $\mathrm{L}_{2} \mathrm{H}_{2}$ trifluoroacetate salt ${ }^{56}$ ), or purchased from Sigma-Aldrich (PDS trifluoroacetate salt and $\mathrm{TMPyP}_{4} p$-toluenesulfonate salt). When documented the molar absorption coefficients were used to measure concentration using the UV absorbance. When not known the powders were weighted and the coefficient was determined (Supporting Figure S1 summarizes all molar extinction coefficients). 1:1 DNA:ligand molar ratios were used to acquire the ESI-MS and the CD data. TMAA and $\mathrm{KCl}$ were first added to the water solution then the proper DNA solution volume is added. Ligands were added one hour after, to ensure starting from pre-formed G-quadruplex. Solutions were stored at room temperature in the dark before analysis. Annealing experiments were also performed on freshly prepared solutions, with $95{ }^{\circ} \mathrm{C}$ heating for $5 \mathrm{~min}$ then leaving the sample for 4 hours at room temperature before further analysis (results didn't change any further when checked after one month left at RT, indicating that equilibrium was reached).

Electrospray mass spectrometry. Native ESI-MS spectra were obtained using a LCT Premier mass spectrometer (Waters, Manchester, UK). The source voltage is set to $2200 \mathrm{~V}$. The desolvation temperature is $60^{\circ} \mathrm{C}$ and the gas temperature is $40^{\circ} \mathrm{C}$. The source pressure is increased to $45 \mathrm{mbar}$ (measured by a Center Two probe, Oerlikon Leybold Vacuum, Cologne, Germany). The sample cone voltage is $200 \mathrm{~V}$. At this voltage TMA adducts on the mass spectra are totally avoided but the $\mathrm{K}^{+}$stoichiometry is not affected. The syringe injection rate is $200 \mu \mathrm{L} / \mathrm{h}$. Shown MS spectra are the sum of 3 min accumulations (1 scan per $1.1 \mathrm{sec}$ ). Savitzky-Golay smoothing has been performed 
with a smooth window of 5 points. Baselines were also subtracted using curves with a polynomial order of 40.

Circular dichroism. CD experiments were run on a Jasco J-815 spectrophotometer using a quartz cell of $2 \mathrm{~mm}$ path length. Shown spectra are the sum of 3 accumulations at $20^{\circ} \mathrm{C}$ with a scan speed of $50 \mathrm{~nm} / \mathrm{min}$ and an integration time of $0.5 \mathrm{~s}$. Data were normalized to molar circular-dichroic absorption $\Delta \varepsilon$ based on DNA concentration: $\Delta \varepsilon=\theta /(32980 \times \mathrm{c} \times \mathrm{l})$, with $\theta$ the CD ellipticity in milidegrees, $\mathrm{c}$ is the DNA concentration in $\mathrm{M}(5 \mu \mathrm{M})$ and 1 is the cell length $(2 \mathrm{~mm})$. Baselines were subtracted using either $100 \mathrm{mM}$ TMAA in water solution or $20 \mathrm{mM} \mathrm{H}_{2} \mathrm{KPO}_{4} / \mathrm{K}_{2} \mathrm{HPO}_{4}+7 \mathrm{O} \mathrm{mM} \mathrm{KCl}$ depending on the experimental conditions. A second linear baseline was removed from the raw data using the mean value obtained for each experiment between $320-350 \mathrm{~nm}$ as no peak was observed in this area. A smoothing was then performed used LOWESS (locally weighted scatterplot smoothing) method. Reported CD spectra display raw data points and the smoothed curve.

Melting monitored by $\mathrm{CD}$. Melting experiments were performed on the same Jasco J-815 spectrophotometer. The temperature ramp was set to $0.4{ }^{\circ} \mathrm{C} / \mathrm{min}$ from 4 to $90{ }^{\circ} \mathrm{C}$. One spectrum per minute was acquired at $100 \mathrm{~nm} / \mathrm{min}$ scan speed with 2 accumulations. The temperature ramp is stopped during each recording. A linear baseline was subtracted from the spectra using the mean value for each experiment between $320-350 \mathrm{~nm}$.

Melting monitored by UV absorbance. Melting experiments on the G-quadruplexes without ligands were also performed on a SAFAS UV $\mathrm{mc}^{2}$ spectrophotometer (Montecarlo, Monaco) equipped with a Peltier temperature controller. The temperature ramp was $0.2^{\circ} \mathrm{C} / \mathrm{min}$ from 4 to $90^{\circ} \mathrm{C}$. The absorbance was monitored at $295 \mathrm{~nm}$.

\section{ASSOCIATED CONTENT}

Supporting Information. Supplementary mass spectra, CD spectra, and CD-melting data as described in the text are available free of charge from www.pubs.acs.org.

\section{AUTHOR INFORMATION}

\section{Corresponding Author}

* Dr. Valérie Gabelica, U869 ARNA, IECB, 2 rue Robert Escarpit, F-33607 Pessac, France; valerie.gabelica@inserm.fr.

\section{ACKNOWLEDGMENT}

This work was supported by the Inserm (ATIP-Avenir Grant no. R12086GS to V.G.), the Conseil Régional Aquitaine (Grant no. 20121304005 to V.G.), and the EU (FP7-PEOPLE-2012-CIG-333611 to V.G.). AM benefited from an Inserm/CRA PhD fellowship. 


\section{REFERENCES}

(1) Biffi, G.; Tannahill, D.; McCafferty, J.; Balasubramanian, S. Nat. Chem. 2013, 5, 182.

(2) Neidle, S. FEBS J. 2010, 277, 1118.

(3) Rodriguez, R.; Müller, S.; Yeoman, J. A.; Trentesaux, C.; Riou, J.-F.; Balasubramanian, S. J. Am. Chem. Soc. 2008, 130, 15758.

(4) Gomez, D.; Wenner, T.; Brassart, B.; Douarre, C.; O’Donohue, M.-F.; El Khoury, V.; Shin-Ya, K.; Morjani, H.; Trentesaux, C.; Riou, J.-F. J. Biol. Chem. 2006, 281, 38721.

(5) Phatak, P.; Cookson, J. C.; Dai, F.; Smith, V.; Gartenhaus, R. B.; Stevens, M. F. G.; Burger, a M. Br. J. Cancer 2007, 96, 1223.

(6) Tua, A.; Phan, A. T. FEBS J. 2010, 277, 1107.

(7) Miller, M. C.; Buscaglia, R.; Chaires, J. B.; Lane, A. N.; Trent, J. O. J. Am. Chem. Soc. 2010, 132, 17105 .

(8) Hänsel, R.; Löhr, F.; Foldynová-Trantírková, S.; Bamberg, E.; Trantírek, L.; Dötsch, V. Nucleic Acids Res. 2011, 39, 5768.

(9) Kan, Z.-Y.; Yao, Y.; Wang, P.; Li, X.-H.; Hao, Y.-H.; Tan, Z. Angew. Chem. Int. Ed. Engl. 2oo6, 45, 1629.

(10) Chaires, J. B. FEBS J. 2010, 277, 1098.

(11) Luu, K. N.; Phan, A. T.; Kuryavyi, V.; Lacroix, L.; Patel, D. J. J. Am. Chem. Soc. 20o6, 128, 9963.

(12) Dai, J.; Carver, M.; Punchihewa, C.; Jones, R. a; Yang, D. Nucleic Acids Res. 2007, 35, 4927.

(13) Lim, K. W.; Amrane, S.; Bouaziz, S.; Xu, W.; Mu, Y.; Patel, D. J.; Luu, K. N.; Phan, A. T. J. Am. Chem. Soc. 2009, 131, 4301.

(14) Chen, M.; Song, G.; Wang, C.; Hu, D.; Ren, J.; Qu, X. Biophys. J. 2009, 97, 2014.

(15) Nakatani, K.; Hagihara, S.; Sando, S.; Sakamoto, S.; Yamaguchi, K.; Maesawa, C.; Saito, I. J. Am. Chem. Soc. 2003, 125, 662.

(16) Rahman, K. M.; Reszka, A. P.; Gunaratnam, M.; Haider, S. M.; Howard, P. W.; Fox, K. R.; Neidle, S.; Thurston, D. E. Chem. Commun. (Camb). 2009, 4097.

(17) Xu, L.; Xu, Z.; Shang, Y.; Feng, S.; Zhou, X. Bioorg. Med. Chem. Lett. 2012, 22, 2988.

(18) Shi, S.; Geng, X.; Zhao, J.; Yao, T.; Wang, C.; Yang, D.; Zheng, L.; Ji, L. Biochimie 2010, 92, 370.

(19) Kaluzhny, D.; Ilyinsky, N.; Shchekotikhin, A.; Sinkevich, Y.; Tsvetkov, P. O.; Tsvetkov, V.; Veselovsky, A.; Livshits, M.; Borisova, O.; Shtil, A.; Shchyolkina, A. PLoS One 2011, 6, e27151.

(20) De Cian, A.; Delemos, E.; Mergny, J.-L.; Teulade-Fichou, M.-P.; Monchaud, D. J. Am. Chem. Soc. $2007,129,1856$.

(21) De Cian, A.; Mergny, J.-L. Nucleic Acids Res. 2007, 35, 2483. 
(22) Granotier, C.; Pennarun, G.; Riou, L.; Hoffschir, F.; Gauthier, L. R.; De Cian, A.; Gomez, D.; Mandine, E.; Riou, J.-F.; Mergny, J.-L.; Mailliet, P.; Dutrillaux, B.; Boussin, F. D. Nucleic Acids Res. 2005, 33, 4182.

(23) Koirala, D.; Dhakal, S.; Ashbridge, B.; Sannohe, Y.; Rodriguez, R.; Sugiyama, H.; Balasubramanian, S.; Mao, H. Nat. Chem. 2011, 3, 782.

(24) Bertrand, H.; Granzhan, A.; Monchaud, D.; Saettel, N.; Guillot, R.; Clifford, S.; Guédin, A.; Mergny, J.-L.; Teulade-Fichou, M.-P. Chemistry 2011, 17, 4529.

(25) Chung, W. J.; Heddi, B.; Tera, M.; Iida, K.; Nagasawa, K.; Phan, A. T. J. Am. Chem. Soc. 2013, 135, 13495 .

(26) Rodriguez, R.; Miller, K. M.; Forment, J. V; Bradshaw, C. R.; Nikan, M.; Britton, S.; Oelschlaegel, T.; Xhemalce, B.; Balasubramanian, S.; Jackson, S. P. Nat. Chem. Biol. 2012, 8, 301.

(27) Pennarun, G.; Granotier, C.; Hoffschir, F.; Mandine, E.; Biard, D.; Gauthier, L. R.; Boussin, F. D. Nucleic Acids Res. 2008, 36, 1741.

(28) Lam, E. Y. N.; Beraldi, D.; Tannahill, D.; Balasubramanian, S. Nat. Commun. 2013, 4, 1796.

(29) Renaud de la Faverie, A.; Hamon, F.; Di Primo, C.; Largy, E.; Dausse, E.; Delaurière, L.; Landras-Guetta, C.; Toulmé, J.-J.; Teulade-Fichou, M.-P.; Mergny, J.-L. Biochimie 2011, 93, 1357.

(30) Verga, D.; Hamon, F.; Poyer, F.; Bombard, S.; Teulade-Fichou, M.-P. Angew. Chem. Int. Ed. Engl. 2014, 53, 994 .

(31) Halder, R.; Riou, J.-F.; Teulade-Fichou, M.-P.; Frickey, T.; Hartig, J. S. BMC Res. Notes 2012, 5, 138.

(32) Piazza, A.; Boulé, J.-B.; Lopes, J.; Mingo, K.; Largy, E.; Teulade-Fichou, M.-P.; Nicolas, A. Nucleic Acids Res. 2010, 38, 4337.

(33) Lopes, J.; Piazza, A.; Bermejo, R.; Kriegsman, B.; Colosio, A.; Teulade-Fichou, M.-P.; Foiani, M.; Nicolas, A. EMBO J. 2011, 30, 4033.

(34) Bharti, S. K.; Sommers, J. a; George, F.; Kuper, J.; Hamon, F.; Shin-ya, K.; Teulade-Fichou, M.-P.; Kisker, C.; Brosh, R. M. J. Biol. Chem. 2013, 288, 28217.

(35) Parkinson, G. N.; Ghosh, R.; Neidle, S. Biochemistry 2007, 46, 2390.

(36) Bazzicalupi, C.; Ferraroni, M.; Bilia, A. R.; Scheggi, F.; Gratteri, P. Nucleic Acids Res. 2013, 41, 632 .

(37) Campbell, N. H.; Karim, N. H. A.; Parkinson, G. N.; Gunaratnam, M.; Petrucci, V.; Todd, A. K.; Vilar, R.; Neidle, S. J. Med. Chem. 2012, 55, 209.

(38) Micco, M.; Collie, G. W.; Dale, A. G.; Ohnmacht, S. a; Pazitna, I.; Gunaratnam, M.; Reszka, A. P.; Neidle, S. J. Med. Chem. 2013, 56, 2959.

(39) Collie, G. W.; Promontorio, R.; Hampel, S. M.; Micco, M.; Neidle, S.; Parkinson, G. N. J. Am. Chem. Soc. 2012, 134, 2723. 
(40) Campbell, N. H.; Parkinson, G. N.; Reszka, A. P.; Neidle, S. J. Am. Chem. Soc. 20o8, 130, 6722.

(41) Parkinson, G. N.; Cuenca, F.; Neidle, S. J. Mol. Biol. 2008, 381, 1145.

(42) Li, J.; Correia, J. J.; Wang, L.; Trent, J. O.; Chaires, J. B. Nucleic Acids Res. 2005, 33, 4649.

(43) Marchand, A.; Gabelica, V. J. Am. Soc. Mass Spectrom. 2014, 25, 1146.

(44) Balthasart, F.; Plavec, J.; Gabelica, V. J. Am. Soc. Mass Spectrom. 2013, 24, 1.

(45) Sun, J.; Kitova, E. N.; Wang, W.; Klassen, J. S. Anal. Chem. 20o6, 78, 3010.

(46) Rosu, F.; Gabelica, V.; Smargiasso, N.; Mazzucchelli, G.; Shin-Ya, K.; De Pauw, E. J. Nucleic Acids 2010, 2010, 1.

(47) Linder, J.; Garner, T. P.; Williams, H. E. L.; Searle, M. S.; Moody, C. J. J. Am. Chem. Soc. 2011, 133, 1044 .

(48) Chung, W. J.; Heddi, B.; Hamon, F.; Teulade-Fichou, M.-P.; Phan, A. T. Angew. Chem. Int. Ed. Engl. 2013, 1.

(49) Karsisiotis, A. I.; Hessari, N. M.; Novellino, E.; Spada, G. P.; Randazzo, A.; Webba da Silva, M. Angew. Chem. Int. Ed. Engl. 2011, 50, 10645.

(50) Lubitz, I.; Borovok, N.; Kotlyar, A. Biochemistry 2007, 46, 12925.

(51) Morris, M. J.; Wingate, K. L.; Silwal, J.; Leeper, T. C.; Basu, S. Nucleic Acids Res. 2012, 40, 4137.

(52) Waller, Z. A. E.; Sewitz, S. A.; Hsu, S.-T. D.; Balasubramanian, S. J. Am. Chem. Soc. 20o9, 131, 12628.

(53) Buscaglia, R.; Gray, R. D.; Chaires, J. B. Biopolymers 2013, 99, 1006.

(54) Monchaud, D.; Yang, P.; Lacroix, L.; Teulade-Fichou, M.-P.; Mergny, J.-L. Angew. Chem. Int. Ed. Engl. 2008, 47, 4858.

(55) Cavaluzzi, M. J.; Borer, P. N. Nucleic Acids Res. 2004, 32, e13.

(56) Tera, M.; Ishizuka, H.; Takagi, M.; Suganuma, M.; Shin-ya, K.; Nagasawa, K. Angew. Chem. Int. Ed. Engl. 20o8, 47, 5557. 